\title{
The research on the performance of cross-shaped concrete columns confined by stirrups under axial repeated loads
}

\author{
Xiaowei Wang ${ }^{1, a}$, Shihua $\mathrm{Wei}^{2}$, Shuai $\mathrm{Lu}^{3}$ and Depeng Zhang ${ }^{4}$ \\ ${ }^{1,2,3,4}$ Civil Engineering and Transportation Institute, Hebei University of Technology, Tianjin \\ awangxw0424@163.com
}

\begin{abstract}
Keywords: axial repeated load, cross-shaped column, confined concrete by stirrups, reinforcement characteristic value

Abstract. Axial repeated loads tests of 5 cross-shaped concrete columns confined by stirrups were carried out. I analyzed the failure process, failure characteristics, skeleton curve and ductility of columns and set up the formulas of ductility coefficient. The results showed that with the increasing of reinforcement characteristic value, the failure type was changed from oblique failure to longitudinal failure, the peak load and displacement of cross-shaped columns increased, the descending segment of skeleton curves turned to be more flat, the calculated results of ductility coefficient were in good agreement with the experimental results. The formula can be used to calculate the ductility coefficient of cross-shaped concrete columns confined by stirrups under axial repeated loads.
\end{abstract}

\section{Introduction}

As a new type of residential structural system, the special-shaped column structure solves the problem of column convex, which combines the aesthetics and practicality of the buildings organically. A proper amount of stirrups is arranged in the special-shaped column to make the core concrete in the three-dimensional stress condition, which increase the strength and ultimate compressive strain of concrete, and effectively improve the seismic performance of special-shaped column structure.The nonlinear analysis of the mechanical behavior of special-shaped columns requires a reasonable model of concrete materials. At present, there are many researches on the performance of concrete confined rectangular columns and circular columns[1]-[7]. The strength, deformation and stress-strain curves of cross-shaped concrete columns confined by stirrups under axial loads are studied in the literature [8]. The study of concrete columns confined by stirrups under repeated loads has not been observed.

Based on the axial repeated loads tests of cross-shaped concrete columns confined by stirrups, this paper studies the mechanical performance of specimens, analyzes the failure process and failure characteristics. The effects of different reinforcement characteristic values on the load-displacement hysteresis curve, skeleton curve and ductility of the specimen are also presented.

\section{Test Design}

The experiment are designed to make five specimens, for the convenience of loading, the section form of both ends of specimens are rectangular, and the middle $720 \mathrm{~mm}$ is in cross shape. The size and reinforcement of the specimen is shown in Figure 1, the longitudinal reinforcement adopts $12 \phi 10$, the reinforcement rate is $2.944 \%$, and the stirrup adopts $\phi 6$. The stirrup spacing $s$, volume stirrups rate $\rho_{v}$ are shown in Table 1.
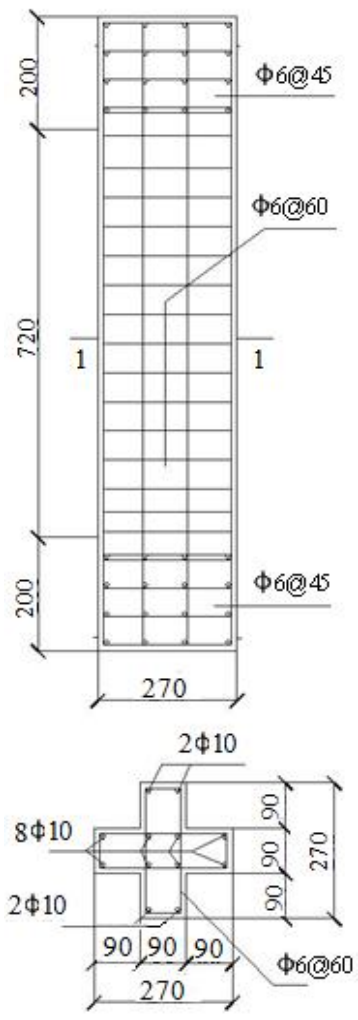

$5000 \mathrm{kN}$ electro-hydraulic servo pressure machine is used to apply axial repeated load. In the middle of the specimens, set two

Fig.1 The size and reinforcement of specimens 
displacement meters of $100 \mathrm{~mm}$ to record the longitudinal displacement of the columns, and in the middle of the specimens, two groups of four displacement meters are arranged to measure the transverse deformation. In the test, the specimens should be strictly placed vertically to ensure the axial compression. The loading scheme uses the equal strain increment full cycle, the strain increment is $1 \times 10^{-3}$. That is, each time the stress is loaded to a predetermined strain, unloaded to 0 , and then loaded into the skeleton curve.

The concrete strength of the test piece is $\mathrm{C} 30$, the measured compressive strength of the concrete is 43.3MPa, and the compressive strength of the prism is $41.4 \mathrm{MPa}$. Through the tensile strength test of steel bars, the yield strength of longitudinal reinforcement is $350.32 \mathrm{MPa}$, the ultimate strength is $509.55 \mathrm{MPa}$, the yield strength of stirrup is $465.32 \mathrm{MPa}$, and the ultimate strength is $632.34 \mathrm{MPa}$. The calculated reinforcement characteristic values that are based on the measured results are shown in table $1\left(\lambda_{v}=\rho_{v} \times f_{y v} / f_{c}, f_{y v}\right.$ is yield strength of stirrups).

Tab.1 Parameters of specimens and results of test

\begin{tabular}{cccccccc}
\hline Number & $s / \mathrm{mm}$ & $\rho_{v} / \%$ & $\lambda_{v}$ & $\begin{array}{c}\text { Failure } \\
\text { characteristic }\end{array}$ & $\mathrm{P}_{\mathrm{u}} / \mathrm{kN}$ & $\varepsilon_{\mathrm{cc}} / 10^{-6}$ & $\mu_{50}$ \\
\hline $\mathrm{Z} 1$ & 60 & 2.314 & 0.2601 & longitudinal & 2194. & 9178 & 1.93 \\
$\mathrm{Z} 2$ & 80 & 1.735 & 0.1950 & longitudinal & 2048. & 9068 & 1.80 \\
$\mathrm{Z} 3$ & 100 & 1.388 & 0.1560 & longitudinal & 1953. & 9032 & 1.69 \\
$\mathrm{Z} 4$ & 120 & 1.157 & 0.1300 & oblique & 1973. & 9042 & 1.57 \\
$\mathrm{Z} 5$ & 180 & 0.771 & 0.0867 & oblique & 1741. & 8854 & 1.14 \\
\hline
\end{tabular}

\section{Failure Process and Characteristic}

Skeleton curve, stirrup stress-strain curve and transverse strain diagram of specimens are shown in Figure 2. It can be seen from the figure, the initial load, stirrup strain and lateral deformation are very small. As the loading continues, the stirrup strain increases as the load increases. When it gets to about $30 \%$ of the peak stress (point A), the skeleton curve is slightly convex, and the slope becomes smaller. The confined concrete plastic deformation occurs when the stress is close to the compressive strength of plain concrete, stirrup strain is about 0.3 times of the stirrup yield strain, the constraint effect is small. The ascending curves of plain concrete and confined concrete are similar in this process. When getting to about $90 \%$ of the peak stress(point B), the first vertical fracture occurs in the specimen, and then the longitudinal crack extension extends, and several new cracks appear, the transverse deformation of the concrete and the stirrup strain growth rate become faster. The transverse strain of the specimen is $400 \times 10^{-6}-800 \times 10^{-6}$ at this time. In the unloading process, the longitudinal deformation has a recovery in a certain degree while deformation of the lateral deformation dose not. Continue to load, the vertical deformation increases and the lateral deformation remains unchanged. When the confined concrete reaches the peak stress (point $\mathrm{C}$ ), the stirrup strain is about 0.5 times of the yield strength, although it has increased greatly, but it has not yielded. The effect of the stirrups in the process is increased, the strength of confined concrete increases $\left(>f_{c}\right)$, the transverse strain of the specimen is $1000 \times 10^{-6}-1500 \times 10^{-6}$. When the stirrups yield (point Y), the stirrups have the greatest effect on the core concrete. With the continuation of the load, the stirrup stress remains constant while the strain increases, and the longitudinal short cracks in the specimen extend, leading to crush of the concrete within the longitudinal short cracks. The core concrete occurred lateral expansive deformation, which squeezes stirrups, so that the stirrups in the horizontal direction out drum and bend. Concrete protective layer began to fall off, stirrups exposed, longitudinal reinforcement buckling, the stirrups of individual specimens are broken and the fractures have necking. At this point, the transverse strain of the specimen is $4000 \times 10^{-6}-5000 \times 10^{-6}$. The transverse deformation of the specimens also has a recovery deformation during the unloading process. As the loading-unloading cycle is carried out, the transverse deformation-longitudinal deformation curve of specimens forms a closed pattern. 


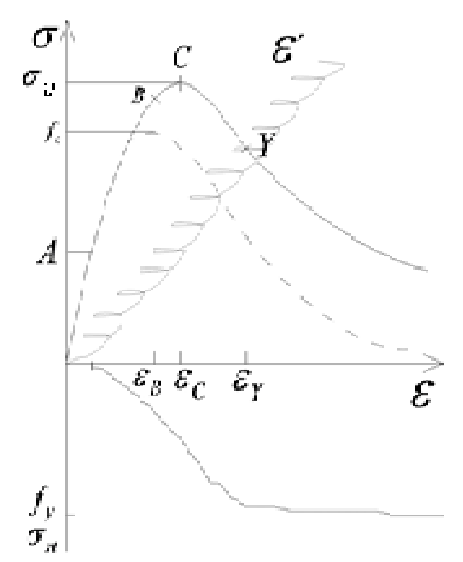

Fig.2 Skeleton curve, stirrup stress-strain curve and transverse strain diagram of specimens

According to the failure conditions and test results of the specimens during the test, it can be concluded that the cracks of cross-shaped concrete columns confined by stirrups under axial repeated loads are not found before the load reaches $85 \%$ of the peak load. When the peak load reaches $85 \%-95 \%$, the specimen begins to show fine longitudinal cracks. As the load increases, the number of cracks increases. After exceeding the peak load, the number of cracks increases and the original cracks extend. The failure characteristics of the specimens are shown in Table 1. It can be seen from Table 1 that Z1, Z2, Z3 occurs longitudinal crushing failure, stirrup characteristic values are 0.2601, $0.1950,0.1560$ respectively. And Z4, Z5 occurs oblique failure, stirrup characteristic values are $0.1300,0.0867$ respectively. From the analysis above, we can see that the specimens with a small stirrup characteristic value are easy to form oblique failure surface. The longitudinal crack of the specimens with relatively large characteristic value extends, causing the concrete between the longitudinal cracks to crush, and the specimens form the longitudinal crushing failure surface.

\section{Load-Displacement Hysteretic Curve and Skeleton Curve}

The load-displacement hysteretic curves and skeleton curves of each specimen are shown in Figure 3. The hysteretic curve of Figure 3(a)-(e) shows that under the axial repeated load, specimen has a large recoverable deformation before reaching the peak load in each cycle, and the residual deformation is small. As the stirrup characteristic value increases, the number of cycles required to reach the peak load increases. The residual deformation of each cycle increases after reaching the peak load and the growth rate of residual deformation decreases with the increase of the stirrup characteristic value.

The peak load $\mathrm{Pu}$ and peak strain $\varepsilon_{\mathrm{cc}}$ of each column are shown in Table 1 . The skeleton curves of each specimen are shown in Figure 3(f). It can be seen from Figure 3(f) that the envelope is basically the same before reaching about $90 \%$ of the peak stress, indicating that the restraint effect of the stirrups on the core concrete is poor. As the loading continues, the effect of the stirrups on the core concrete is 


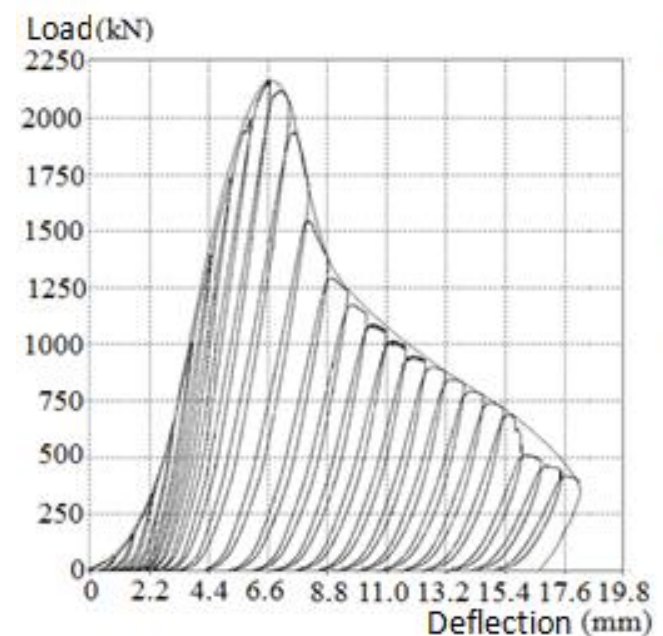

(a) Z1

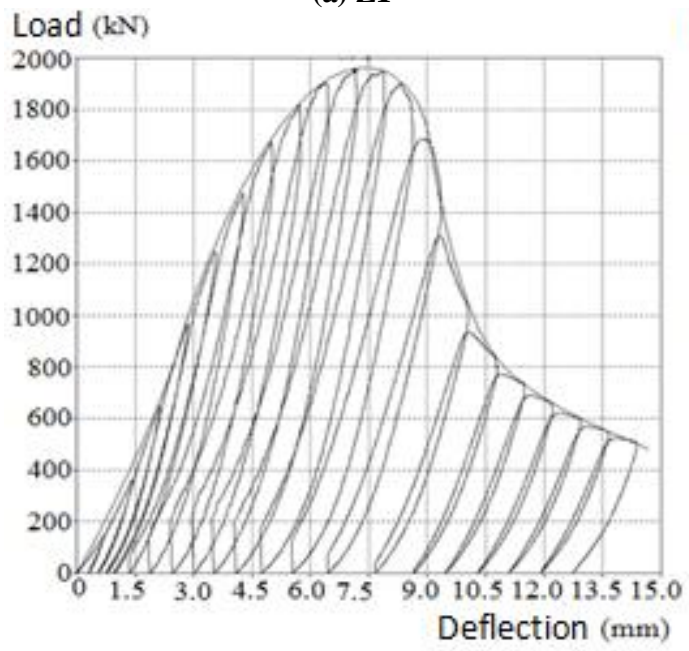

(c) $\mathbf{Z 3}$

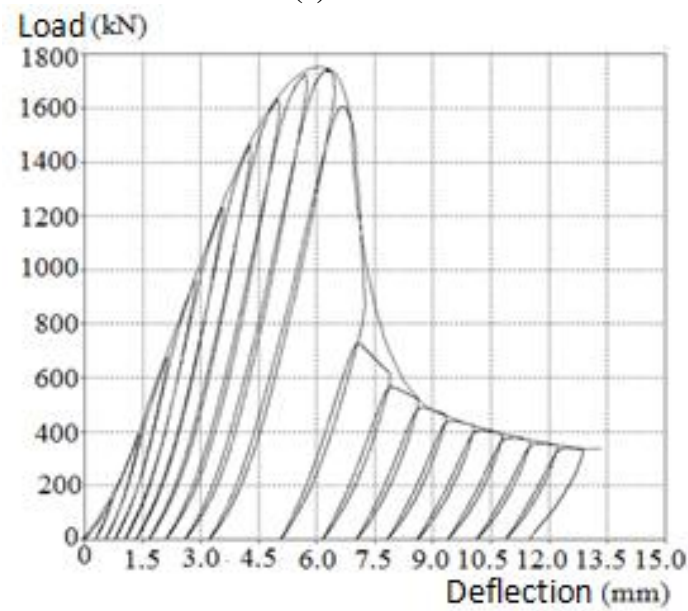

(e) $\mathbf{Z 5}$

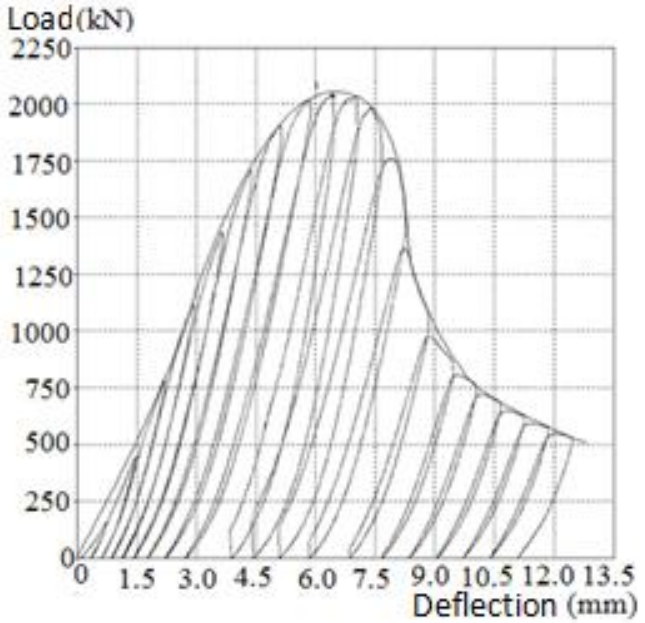

(b) $\mathbf{Z 2}$

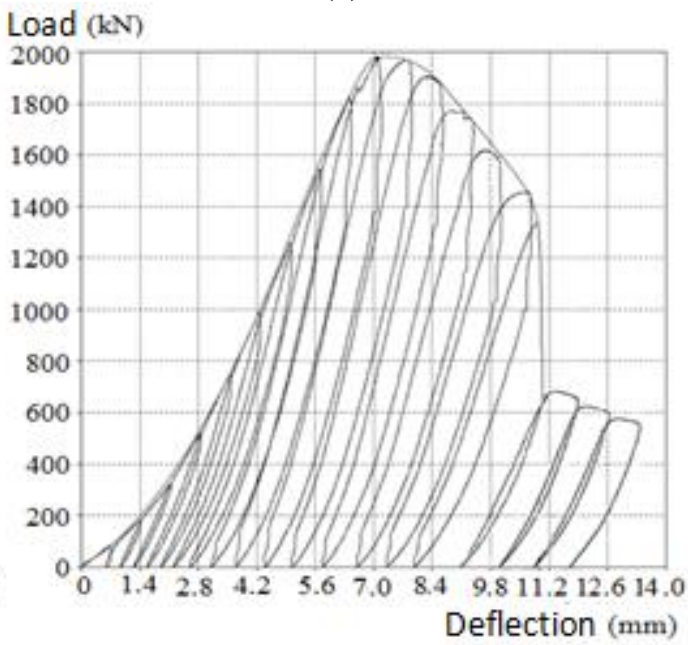

(d) $\mathbf{Z 4}$

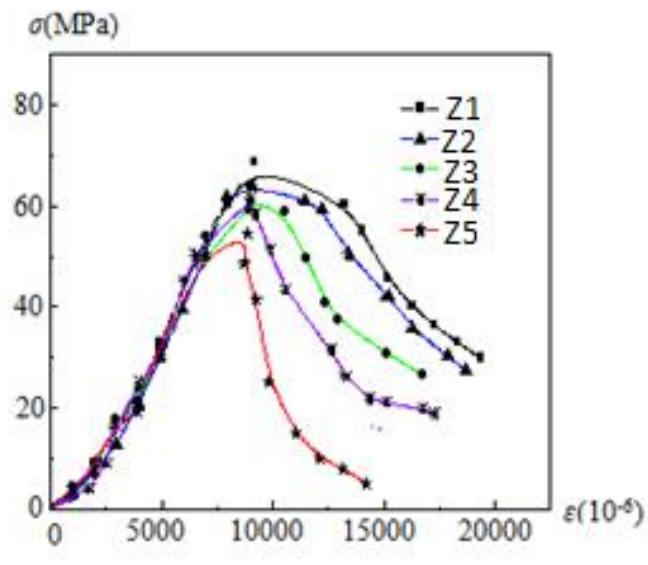

(f) The comparison of skeleton curves

Fig.3 Load-displacement curves and skeleton curves

on the enhanced. The larger the stirrup characteristic value is, the stronger the effect of the stirrups on the concrete. Based on the same concrete strength, with the increase of the stirrup characteristic value, the peak stress and the peak strain of the specimens increase, and the descending section of the skeleton curve becomes more flat and ductility increases. 


\section{The Ductility of Specimen}

In this paper, the ductility coefficient is used to characterize the deformation ability after the peak load of the specimen, and the influence of stirrup characteristic value is studied. $\varepsilon_{50} / \varepsilon_{c c}$ is defined as the ductility coefficient of the cross column $\mu_{50} . \varepsilon_{50}$ is the strain with the specimen bearing capacity decreased to $50 \%$ of the peak force, $\varepsilon_{c c}$ is the peak strain of the specimen. The ductility coefficient of the specimen is shown in Table 1. Under axial repeated load, the relationship between the ductility coefficient of the specimen and the stirrup characteristic value is shown in Figure 4. From the experiment results, the larger the stirrup characteristic value is, the more flat the descending section of the specimen skeleton curve, the greater the ductility coefficient.

Through the regression analysis of the experiment data, the relationship between the

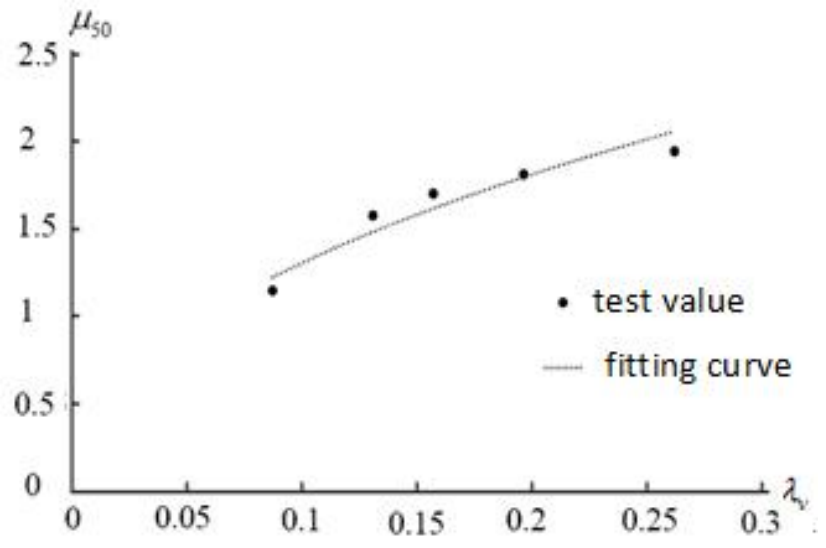

Fig.4 The relationship between the ductility coefficient and stirrup characteristic value ductility coefficient and the stirrup characteristic value under axial repeated load is obtained as follow:

$$
\mu_{50}=7.06 \lambda_{v}^{1.5}+1.2
$$

The correlation coefficient is 0.9366 and the standard deviation is 0.0727 . It can be concluded that the calculated results are in good agreement with the experimental results and can be used to calculate the ductility coefficient of the cross-shaped concrete columns confined by stirrups under the axial repeated loads.

\section{Conclusions}

In this paper, the experimental study of cross-shaped concrete columns confined by stirrups under axial repeated loads is carried out, and the main conclusions are drawn as follows:

1.The specimens with larger stirrup characteristic value are prone to longitudinal failure while specimens with smaller stirrup characteristic value are prone to oblique failure. The peak load and strain increase with stirrup characteristic value becomes larger.

2.The load-displacement skeleton curve is basically the same before reaching about $90 \%$ of the peak stress, and with the increase of stirrup characteristic value, the decline section of skeleton curve is more flat and ductility increases.

3.The formula of ductility coefficient is established in this paper. The calculated results are in good agreement with the experimental results, which can be used to calculate the ductility coefficient of the cross-shaped concrete columns confined by stirrups under the axial repeated loads.

\section{Acknowledgements}

This work was financially supported by the Hebei Natural Science Foundation (E2014202178).

\section{References}

[1] Sheikh S A, Uzumeri S M. Analytical model for concrete confinement in tied columns[J]. J Structural Division, ASCE, 1982, 108(12):2703-2722.

[2] Mander J B, Priestley M J N, Park R. Theoretical stressstrain behavior for confined concrete[J]. Journal of Structural Engineering, ASCE, 1988, 114(8):1827-1849. 
[3] Saatcioglu M, Razvi R. Strength and ductility of confined concrete[J]. Journal of Structural Engineering, ASCE, 1992, 118(6):1590-1607.

[4] Park R, Priestley M J N, Gill W D. Ductility of squareconfined concrete columns[J]. Journal of the Structural Division, ASCE, 1982, 108(4):929-950.

[5] Zheng Wenzhong. Design method for confined concrete column with different yield strength stirrups[J]. Journal of Building Structures, 2016, 37(12):74-82.

[6] Zhang Xinghu. Experiment on seismic behavior concrete columns confined with high-strengths spiral stirrups[J]. Journal of Architecture and Civil Engineering, 2013, 30(6):21-27

[7] Qi Yue, Zheng Wenzhong. Experimental study of the seismic behavior of concrete columns with high strength core under low cyclic loading[J]. Journal of Hunan University:Natural Science, 2009, 36(12):6-12

[8] Wang Xiaowei. Experimental and theoretical research on performance of axially specially shaped columns confined by stirrups[D]. Tianjin University, 2009. 